Florian Arendt* and Agnes Obereder

\title{
Attribute agenda setting and political advertising: (Dis)association effects, modality of presentation, and consequences for voting
}

DOI 10.1515/commun-2016-0024

\begin{abstract}
We investigated the attribute agenda-setting (AAS) effect of political advertising. Individuals $(N=209)$ participated in an experiment and were exposed to six political print advertisements, which were manipulated to represent either a text-only, visual-only, or visual-plus-text version. As expected, we found that AAS led to association effects in which advertising content strengthened mental links between the party and advertised issues. However, we also present evidence for disassociation effects in which non-advertised issues were mentally delinked from the party. Importantly, AAS was dependent on the modality of presentation with information presented verbally plus visually (dualmodal presentation) eliciting the strongest effects. Furthermore, the strength of the AAS effect predicted voting intentions for that party, but only in those who rated the advertisements favorably. We discuss the present study's contribution to the AAS literature with regard to association and disassociation effects, modality of presentation, and AAS's consequences on voting.
\end{abstract}

Keywords: attribute agenda setting, political advertising, visuals, modality of presentation, voting

\section{Introduction}

Political advertising is the dominant form of direct communication between political parties and citizens. It is a tool to present political ideas and goals to citizens without the necessity of relying on intervening third parties, such as

\footnotetext{
*Corresponding author: Florian Arendt, Department of Communication Science and Media Research, University of Munich (LMU), E-mail: florian.arendt@ifkw.Imu.de

Agnes Obereder, Department of Communication, University of Vienna, E-mail: agnes.obereder@univie.ac.at
} 
journalists. From the strategic perspective of campaigners, political advertising is thus a promotional device which can be used to influence factors such as citizens' perceptions of issue ownership with the ultimate goal of persuading and mobilizing them (Kaid, 2004).

Attribute agenda-setting (AAS) theory can be used to describe the processes underlying issue-specific advertising effects. On a most basic level, the theory predicts that political advertising may influence how citizens think about a political party by selecting and placing emphasis on certain issues and ignoring others. The emphasis on target issues may thus contribute to the development, reinforcement, and alteration of specific issues becoming mentally linked to the party in citizens' minds (McCombs, 2005). This so-called AAS effect provides the focus of the present study. We investigated political advertising's ability to set the agenda of issue-attributes for political parties. We argue that the advertisements' emphasis on target issue-attributes can lead to an association effect (representing intended attribute gains), where the advertised target issueattributes become mentally linked to the party in the citizens' minds. However, we hypothesized that a disassociation effect can also occur by displacing other non-advertised issue-attributes (sometimes representing unintended attribute losses). Therefore, we theorized that AAS could consist of these two phenomena. Importantly, we questioned whether AAS depends on the modality of presentation (text-only, visual-only, text-plus-visual). Based on previous research outlined below, we predicted the strongest AAS effects for text-plus-visual advertisements.

The present study contributes to the AAS literature in five important ways. First, we tested whether AAS also produces disassociation effects. To our knowledge, this study is the first to investigate association and disassociation effects as dimensions of AAS under a controlled experimental setting. Second, we studied a possible moderator (modality of presentation) of AAS. Third, we also investigated the consequences of AAS effects on voting decisions. We tested whether the strength of the AAS effect in turn influences voting intentions for the advertised party. Fourth, the agenda-setting objects in previous research are established concepts most of the time (e.g., real politicians such as the president). As we will outline below, the use of a new AAS object (i.e., a novel party) to which participants have no prior knowledge allows for the study of the AAS process under a controlled setting. Fifth, most AAS research uses journalistic news content as the agenda setter. However, there has been a call to widen the perspective into "new arenas" (McCombs, 2005, p. 552). As McCombs noted, there are many agendas in contemporary society relevant to public affairs. We try to contribute to the widening of the AAS perspective by using political print advertising content. Print advertisements (e.g., in newspapers, 
magazines, or on posters on billboards) are an important means of political communication in numerous countries, especially in Europe (Van den Bulck, 1993).

\section{Attribute agenda setting}

Agenda setting is a theory about the transfer of salience. According to the basic agenda-setting hypothesis, objects that are prominent in the media become prominent in citizens' minds (McCombs and Shaw, 1972). The object agendas can be composed of any set of objects, including political parties (McCombs, Llamas, Lopez-Escobar, and Rey, 1998). Beyond the agenda of objects, however, there is also an agenda of attributes. Each object can have a number of attributes. These attributes (e.g., issues) fill out the picture of each object (e.g., political party) in citizens' heads (McCombs et al., 1998). It is important to note that as objects vary in salience, so do their attributes (McCombs and Shaw, 1993). Some attributes may be emphasized by political advertising, others may be mentioned only in passing, and many others may be ignored (see McCombs, Lopez-Escobar, and Llamas, 2000). By the campaigners' use of selection, emphasis, exclusion, and elaboration (see Tankard, Hendrickson, Silberman, Bliss, and Ghanem, 1991), specific attribute agendas for each political party are constructed and medially diffused by the means of advertising. It is important to note that political advertising does not dictate what citizens will think about political parties, but it may direct, guide, or orient what citizens deem worthy of thinking and feeling about (McCombs et al., 1998).

Although agenda-setting research has started to investigate the consequences of news agendas, the core idea of a transfer of salience from one agenda to another has been opened up to cover a wide variety of topics as diverse as corporate reputations, professional sports, and religious beliefs (McCombs, 2005). Political advertising is the topic of focus of the present paper.

\section{Party-issue links}

Research has accumulated evidence showing that political advertising can influence citizens' perceptions of political objects such as candidates, parties, or events (e.g., Brosius, Holicki, and Hartmann, 1987; Kaid, 1999, 2004). Thus, attributes of political parties such as issue associations are not static, but dynamically change, depending on environmental stimuli such as political adver- 
tising. For example, Walgrave, Lefevere, and Nuytemans (2009) showed that issue ownership is a dynamic process that can be influenced by mass-mediated information. Participants watched a manipulated audiovisual news item in which political parties offered their parties' stances on six issues. The researchers were able to reveal how news exposure led to substantial shifts in the perceptions of issue ownership, especially on issues that were not owned by any of the parties.

\subsection{Association effects}

A great deal of empirical evidence supports the assumption that exposure to political advertising can influence issue-specific knowledge (e.g., Atkin and Heald, 1976; Kaid, 1999; Martinelli and Chaffee, 1995). Following the premises of AAS theory (McCombs and Shaw, 1993), we assumed that political advertising could influence how citizens would think about a political party by selecting and placing emphasis on certain attributes and ignoring others. Thus, the emphasis on target attributes should lead to an association effect, where the advertised attributes become mentally linked to the party in citizens' minds.

A conception of memory as a network of connected concepts is helpful in explaining association effects. Network models of memory (see McNamara, 2005, for a review) assume that concepts are linked with other concepts in a network where each node represents a concept. Importantly, objects and attributes are concepts. A basic assumption is that links between concepts are strengthened each time they are activated by media content in tandem (Domke, Shah, and Wackman, 1998; Greenwald et al., 2002). Thus, based on repeated, simultaneous activation of object-attribute pairs, their mental association will increase.

Furthermore, as the number of separate linkages to any particular concept increases, so does the likelihood that the concept will be activated. For example, if a campaign strengthens the associations between a party and different, but related specific attributes such as 'nature', 'environmental care', 'protection of the natural environment', and 'environmental sustainability', mental links between the party and these specific attributes are strengthened. In addition, concepts which are associatively related to these specific attributes, such as the more inclusive and broader concept of 'environment', also become mentally linked to the party through the process of spreading activation (McNamara, 2005): When a specific attribute (e.g., 'environmental sustainability') is brought into focal awareness by a party's advertising content, corresponding concepts are activated in the memory. The activation radiates out from the particular 
concept related to the attribute along the associative pathways to other nodes. According to Collins and Loftus (1975), activation spreads out along the pathways of the network in a decreasing gradient. Importantly, spreading activation increases the probability that related concepts (e.g., the more inclusive 'environment') become activated as well. Thus, by advertising specific issues such as 'environmental sustainability', political advertising also influences mental links involving broader concepts such as 'environment'.

Over time, regular exposure may contribute to the development of partyissue memory traces in so far as concepts might become associated in citizens' minds. Thus, regular exposure may contribute to the forming of new partyissue links. Once developed, mental party-issue associations can be re-activated by subsequent media exposure via priming (Roskos-Ewoldsen, RoskosEwoldsen, and Carpentier, 2009). Media priming refers to the residual, often unrecognized consequences of media exposure on subsequent judgments and behaviors.

[H1] Citizens exposed to political advertising associating a political party with specific target issues will mentally link the party with the advertised target issues.

\subsection{Disassociation effects}

The focus of previous research has clearly been on association effects. A disassociation effect, however, may also occur by displacing other important attributes that are not advertised. We already pointed to the fact that political advertising may emphasize some issues, but others may be mentioned only in passing, and many others may be ignored (see McCombs, Lopez-Escobar, and Llamas, 2000). When issues are ignored, recipients have no chance of being able to learn the mental associations that are related to the non-advertised issues.

Consider a campaign of a newly founded political party. Citizens have no (or only a few) prior mental associations stored. Political advertising can thus fill out a new picture of the party in the citizens' heads (McCombs et al., 1998). When there is a tabula rasa-like mental state with regard to the party, different issues are similarly likely to be associated with the party. This may result in moderate levels of party-issue links: "I think that it is, in principle, possible that the party is concerned with issues A, B, C, D, E, etc."

We propose that before new information about the party is acquired, there may be a state of uncertainty. Uncertainty can be conceptualized as a lack of 
knowledge or, on a more complex level, a lack of knowledge needed to form judgments or to direct behavior (Atkin, 1973). Print advertising content promoting specific party-issue links may decrease uncertainty by strengthening mental associations (association effect). However, this increased level of certainty may decrease the perceived possibility of associations between the party and non-target issues: "I know that the party is concerned with A and B, and thus I think that it is less likely that the party is also concerned with C, D, and E." For example, a party with increasing levels of strength of association with 'law and order' may be related to decreasing levels of strength of association with 'minority rights'.

Network models of memory can explain disassociation effects. According to Collins and Loftus (1975), activation decreases over time and/or with intervening activity. When political parties place their emphasis on target issues and ignore non-target issues, there is obviously much time between the last simultaneous activation of the party and the non-advertised issue; or there had never been a simultaneous activation in newly founded parties. In addition, intervening activities (e.g., activation of target attributes) happened. As there is a lack of empirical knowledge on dissociation effects, the present paper tries to contribute to the AAS literature by testing a further hypothesis.

[H2] Citizens exposed to political advertising associating a political party with specific target issues will disassociate the party from other non-advertised issues.

In a nutshell, we argue that AAS can consist of two related phenomena. Exposure to object-attribute associations in the environment (e.g., party-issue pairings in advertising content) can lead to strengthened mental object-attribute links (association effect). However, exposure may also lead to a disassociation effect where object-attribute pairings not encountered in the symbolic environment may weaken their corresponding mental associations.

\section{Modality of presentation}

Although there seems to be scholarly agreement that mass-mediated content can influence the attributes associated with specific parties (see above), there is hardly any evidence on the moderating impact of the modality of presentation in the AAS process. The present study thus focused on the question as to whether political print advertising content shows different AAS effects depend- 
ing on the modality of presentation (text-only, visual-only, text-plus-visual). Although political print advertisement content relies heavily on visual content, the degree can vary from advertisements having only verbal content to advertisements with an emphasis on images, and further to advertisements with an emphasis on visual-plus-verbal content (see Brosius et al., 1987; Kaid, 2004; Van den Bulck, 1993).

Of primary importance for this research focus is a definition of 'visuals'. Coleman (2010) defined visuals as "media content that is processed by the eye alone” (p. 236). Thus, visuals include elements such as photographs, drawings, maps, and graphics. In contrast, text refers to verbal content and includes written words (e.g., slogans). One important difference between text and visuals is verbal language's elaborate and explicit set of syntactic devices for making explicit propositional statements (Messaris and Abraham, 2001).

Lippmann (1922) coined the famous phrase "pictures in our heads", which subsequent agenda-setting scholars have repeatedly referred to (e.g., McCombs et al., 1998). Interestingly, the importance of visuals has remained undervalued until recently (see Coleman, 2010). We predicted that the combination of visual plus textual elements in advertising content elicits the strongest AAS effect. This assumption is based upon two related lines of research: Visual framing and dual-modal presentations. We argue that both lines of research support the assumption that visuals help to strengthen mental associations in memory.

\subsection{Visual framing}

Today, framing theory has emerged as one of the lifelines for research on massmediated visuals (Coleman, 2010). Framing means to "select some aspects of a perceived reality and make them more salient” (Entman, 1993, p. 52). Political advertising can select, accentuate, or exclude some aspects (i.e., attributes) by the use of visuals (i.e., frame building). This, in turn, can evoke a specific perspective on a party (i.e., framing effects). It becomes obvious that there is a strong relationship between framing and AAS (see McCombs, 2005, for a discussion of the similarities).

According to this view, framing effects occur when a photograph, graphic, or drawing suggests a particular interpretation of an object (Scheufele and Tewksbury, 2007). Especially for advertising content, which mostly relies on situations without high involvement (Krugman, 1965), including low-effort processing (Petty and Cacioppo, 1986), an important effect of visuals can be that they capture attention and elicit interpretations. This can lead to the activation of additional associations in memory. Stated differently, more specific 
attributes (e.g., environmental sustainability) become mentally linked with the party due to visual framing's potential to elicit interpretations. We already noted that as the number of separate linkages to an object (e.g., party) increases, so does the likelihood that the party will be mentally linked with the broader, more inclusive attribute (e.g., environment). Thus, the elicitation of interpretations can lead to a richer set of associations in memory, which should lead to a strengthening of the party-issue association by spreading activation (see also Anderson, 2007).

\subsection{Dual-modal presentation}

There is a second, but highly intertwined line of research supporting this claim. These studies were on how verbal and visual environmental input information is cognitively processed in multiple modalities of presentation. What is most central for the present paper is the finding that dual-modal presentations (visuals plus verbal information) can enhance the memory for, and comprehension of, the presented information (Burgoon, 1985; Gunter, 1987). Importantly, visuals can help encoders to build better mental representations (Gunter, 1987; Paivio, 1986). According to this explanation, adding relevant visual information to the verbal information improves learning by stimulating new associations in memory because the visuals provide additional learning cues. Presenting information via two channels may thus create meanings that go beyond the information provided by each individual channel. Research on dual-modal presentation led to the same predictions made by visual framing theory and thus also supports the notion of stronger effects from a combination of text-plusvisual content (see Abraham and Appiah, 2006).

\subsection{Modality of presentation as a moderator}

Based on these two (highly intertwined) lines of research, we predicted that political print advertising content using visual-plus-verbal information should elicit the strongest AAS effects specified in H1 and H2. Visual-only advertisements should show weaker AAS effects because of the absence of syntactic devices for making explicit propositional statements (Messaris and Abraham, 2001). Text-only advertisements should show weaker effects because of the absence of visuals' ability to create meanings that go beyond information provided by text. 
[H3] The modality of presentation moderates AAS effects of political print advertising content in the way that visual-plus-verbal advertisements should elicit the strongest AAS effects specified in $\mathrm{H} 1$ and $\mathrm{H} 2$.

\section{Consequences for voting}

It is important to investigate possible consequences of AAS (McCombs, 2005). Voting is one of the most important activities in terms of participating in the political process (Powell, 2000). Based on the theory of issue ownership (Budge and Farlie, 1983; Petrocik, 1996), we theorized a link between AAS effects and voting preferences. Of interest for the present paper, this theory provides an account of voter behavior based on the role of issue ownership (Belanger and Meguid, 2008). It is argued that citizens build their voting preferences by evaluating the competence that each political party has in handling specific issues. Citizens identify the party that they think is the most competent proponent of a particular issue.

We argue that AAS is one part in a complex process. AAS can contribute to the mental links between a party and particular issues. A further step is the construction of a voting decision. We already noted the claim made by agendasetting theorists that media content does not dictate what citizens will think about political parties, but it may direct, guide, or orient what recipients deem worthy of thinking about (McCombs et al., 1998). Thus, even when political advertising strengthens the mental link between a party and an issue, only those who have a favorable attitude concerning the advertised content might show an increase in voting intentions. Thus, we focused our attention on one possible moderator of the relationship between AAS effects and the consequences for voting intentions. We predicted that the evaluation of the advertising content moderates the impact of the strengthened party-issue links on voting intentions.

Previous consumer research has indicated that recipients of an advertising message can develop an "attitude toward the ad", which in turn exerts an influence on subsequent measures of advertising effectiveness such as brand attitude and purchase intentions (Lutz, MacKenzie, and Belch, 1983). In the political realm, 'purchase intentions' can be understood as voting intentions. We wanted to test whether a positive evaluation of the print advertising content enhances the consequences of AAS effects on voting intentions. In fact, we speculated that the strengthened mental links between the new political party and issues predicts that voting intentions would be stronger in individuals with 


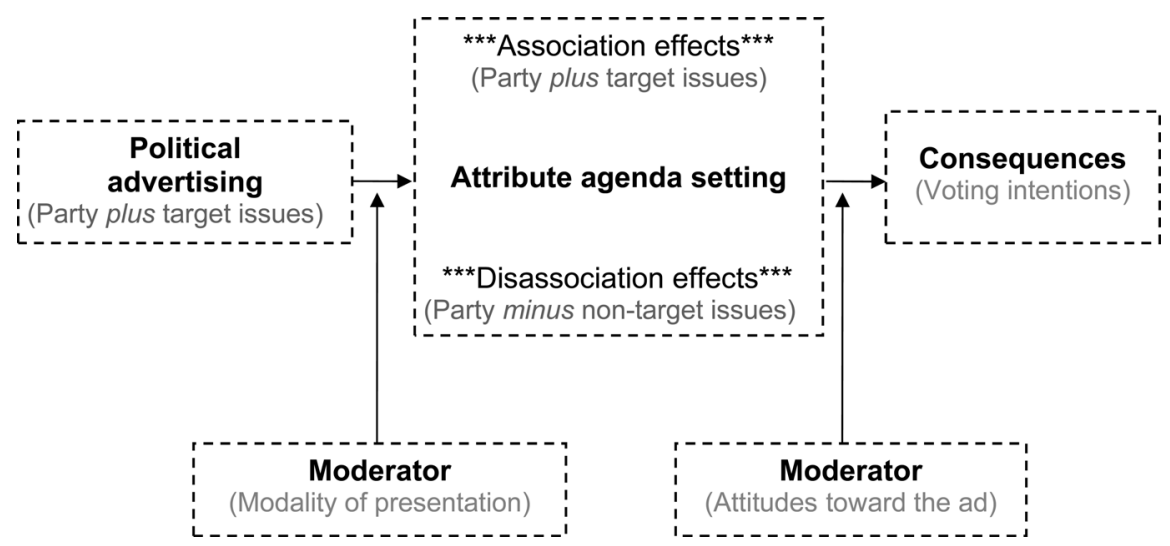

Figure 1: Visualization of the model describing the AAS process.

Political advertising promoting specific party-issue links can lead to the AAS effect by strengthening the mental link between the party and the advertised (target) issues and by disassociating (non-target) issues that are not advertised. AAS in turn can have important consequences, for example, on voting intentions. Although both effect paths can be moderated by a number of factors, we tested (1) whether political advertising's AAS effects are moderated by the modality of presentation, and (2) whether the effect of the strengthened party-issue links (AAS) on voting intentions is moderated by attitudes toward the ad.

a more positive evaluation of the advertising content (e.g., a perception of the party promoting the 'right' issues). When participants dislike the advertising content, they may nevertheless understand that the party stands for the advertised issues (AAS), but they do not show more favorable intentions in terms of voting for the party (the consequences of AAS).

[H4] Mental party-issue links strengthened by political print advertising content influence voting intentions for that party.

[H5] The effect specified in H4 is moderated by attitudes toward the ad.

A graphical depiction of all five hypotheses can be found in Figure 1.

\section{Overview of the empirical work}

We used an experimental design with three groups to test these predictions. Participants were exposed to six political print advertisements of a newly created political party using text-only, visual-only, or text-plus-visual advertise- 
ments. Before and after watching the ads (pre-post design), we measured participants' mental associations regarding the party in terms of target and nontarget attributes. Thus, a 3 (modality of presentation: text-only, visual-only, text-plus-visual) $\times 2$ (type of attribute: target or non-target issues) $\times 2$ (time of measurement: before or after exposure) mixed design was utilized. The modality of presentation was a between-subjects factor. The type of attribute and time of data collection were within-subjects factors.

We used a newly created political party as the object of focus because it allowed us to study the AAS process under a controlled setting. Citizens have a lack of knowledge regarding the issues that a novel party endorses. Advertising content does not compete with other sources of knowledge. The use of newly created objects is an often-utilized strategy to study a process (e.g., Gregg, Seibt, and Banaji, 2006).

\section{Method}

\subsection{Participants}

A total of $N=209$ individuals participated in a web experiment. They were invited to participate through online advertisements on social networking sites posted by students of an introductory course on communication research. Unfortunately, 13 participants did not fill out the whole questionnaire, resulting in a final sample size of $N=196$ completing the survey. Of these participants, $69.4 \%$ were female. The participants ranged in age from 15 to $59(M=23.56$, $S D=5.99$ ). The sample was well educated. Only a small portion of the sample had no high school diploma (7\%), 61\% had a high school diploma, and 30\% had a university degree ( $2 \%$ were not distinguishable in terms of these categories). The sample showed a slight leaning toward the political left ( $M=2.88$, $S D=1.18$ ) measured on a 7-point scale ranging from left (coded as 1 ) to right (coded as 7). Most of the participants (84.2\%) were students at a large European university.

\subsection{Experimental manipulation}

We tested AAS for a new political party named the DPÖ (Deine Partei für Österreich - Your Party for Austria). This is a fictitious party that does not exist. A visual logo was designed (see the Appendix) and used on all advertisements, regardless of experimental condition. We constructed a total of six advertise- 
ments for each condition. Three advertisements targeted the issue of education and the other three targeted the issue of the environment. We used the same slogans in the text-only and the visual-plus-text condition (education: "Fair access to universities", "Education for everyone", "Better conditions for apprentices”; environment: "More bikeways", “Think sustainable”, "Green instead of grey"). We utilized a forced-exposure situation. Each print advertisement was shown for six seconds in random order. We used a rather short exposure time to resemble real exposure situations (e.g., mostly only a few seconds are allocated to the reception of an advertisement, see Lessinger, Moke, and Holtz-Bacha, 2003).

The text-only versions contained the slogan and the logo, and the background of the advertisements was yellow, which was the color of the party. There is no real Austrian party using this color scheme. The visual-only versions consisted of a visual (see the Appendix) and the logo. The visual showed a picture congruent with the slogan used in the text-only version. For example, for the advertisement with the slogan "More bikeways" in the text-only version, a visual showing a bikeway was used in the visual-only version. The visualplus-text version contained the slogan, the visual, and the logo.

It must be noted that we used visual images juxtaposed with the verbal statements for dual-modal presentation. We constructed the advertisements with the intention being that the visual information would 'double up' with the verbal statement. It was not the goal of the present study to test whether visuals could elicit different new meanings in the opposite direction to the verbal statement (see Abraham and Appiah, 2006).

\subsection{Measures}

Target attributes. We asked the participants, "Which of the following issues do you associate with DPÖ?" Respondents could indicate their answer on a 7point scale ranging from not at all associated (coded as 1) to associated (coded as 7). We used three items per topic presented in random order (education: education, apprenticeship, study; environment: environment, sustainability, nature). We calculated the mean on those responses measured before $(M=$ 3.65, $S D=1.45, \alpha=.88)$ and after $(M=5.30, S D=1.62, \alpha=.95)$ exposure.

Non-target attributes. We used the same method reported above for target attributes, but with ten different issues (migration, health, work, living, justice, family, economy, foreign affairs, culture, and infrastructure). The items were presented in the same list as the target attributes and in random order. We measured these mental links before $(M=3.96, S D=1.08, \alpha=.83)$ and after $(M=3.53, S D=1.15, \alpha=.86)$ exposure. 
Voting intentions. We questioned whether participants would vote for the party: "Imagine that there is an election next Sunday. The DPÖ will run for election. How much do you rate the likelihood that you will vote for this party?" Participants could answer on a 7-point scale ranging from very low (coded as 1) to very high (coded as 7). Voting intentions were measured before $(M=1.75$, $S D=1.18)$ and after $(M=2.93, S D=1.70)$ exposure.

Attitude toward the ad. We asked participants to evaluate the advertising content. Participants could rate the content on a 5-point semantic differential scale with nine items (e.g., positive/negative, good/bad, meaningful/meaningless) ranging from the positively valenced attribute (coded as 1 ) to the negatively valenced attribute (coded as 5$)$. We averaged the responses $(M=2.65$, $S D=0.79, \alpha=.90)$.

\section{Results}

\subsection{Attribute agenda setting}

We predicted that citizens exposed to political advertising associating a political party with specific target issues increases the likelihood that participants will associate the party with the advertised target issues (H1), will disassociate the party from other non-advertised issues $(\mathrm{H} 2)$, and that the modality of presentation moderates these effects (H3). We used a 3 (modality of presentation) $\times 2$ (type of attribute) $\times 2$ (time of measurement) mixed-factor ANOVA to test these hypotheses. We predicted a significant three-way interaction. This is what was found: $F(2,199)=5.16, p=.007, \eta^{2}=.05$. This interaction effect indicates that the advertising effect operationalized as change over time was moderated by the type of attribute and by the modality of presentation. ${ }^{1}$ Figure 2 visualizes this interaction. We now probe this interaction effect by looking at the advertising effects separately for each modality of presentation.

As Figure 2 (left-hand diagram) shows, exposure to print advertising content led to substantial association effects for target attributes, as predicted by H1. All modalities of presentation produced significant effects: The text-plusvisual version produced the strongest effect, $t(70)=11.92, d=1.36, p<.001$, followed by the text-only, $t(63)=7.75, d=1.08, p<.001$, and visual-only version,

1 As a three-way interaction qualifies the interpretation of the simple main effects, we do not report these ANOVA coefficients. This analysis can be obtained upon request. All other relevant tests (including two-way interactions) are reported in the main text. 
TARGET ISSUES

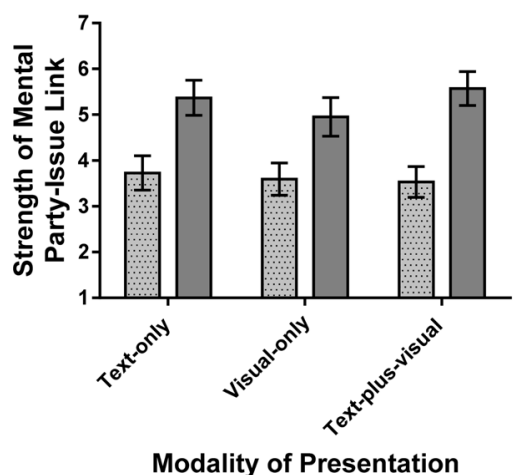

NON-TARGET ISSUES

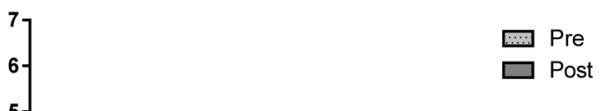

Figure 2: Attribute agenda-setting (AAS) effect.

The strength of mental party-issue links for each type of modality of presentation (textonly, visual-only, visual-plus-text) and for each type of issue (target issues, non-target issues) is shown. The figure shows pre- as well as post-measured scores. The left-hand diagram visualizes the association effects on target issues. The right-hand diagram visualizes the disassociation effects on non-target issues. Error bars represent confidence intervals (95\%).

$t(66)=5.76, d=0.85, p<.001$. These three effect sizes are large based on Cohen's (1988) definition. This supports H1.

Exposure to print advertising content also led to disassociation effects for non-target attributes, as predicted by H2. This is visualized in Figure 2 (righthand diagram). Only two modalities of presentation produced significant effects. The text-plus-visual version produced the strongest disassociation effect, $t(63)=-4.18, d=-0.46, p<.001$, followed closely by the text-only version, $t(63)=-3.23, d=-0.40, p=.002$. Although the visual-only coefficient points in the predicted direction, the visual-only version produced the weakest disassociation effect and failed to reach significance, $t(66)=-1.47, d=-0.20$, $p=.15$. These three effect sizes are substantially smaller compared to the association effects reported above, and can be deemed as small according to Cohen (1988). These findings only partially support H2: Only text-plus-visual and textonly advertisements lead to significant disassociation effects.

$\mathrm{H} 3$ predicted that the modality of presentation moderates the advertisements' impact. We calculated two-way interactions between the time of measurement (pre, post) and the modality of presentation for each issue type. First, we found a marginal significant interaction effect for target issues (see Figure 2, left-hand diagram), $F(2,199)=2.82, p=.06, \eta^{2}=.03$. As already noted above, all three modalities of presentation produced strong effects (text-plus-visual $d=$ 
1.36, text-only $d=1.08$, visual-only $d=0.85$ ). The interaction effect, which approaches significance, indicates that these three effects differ in size, showing a statistical trend. Second, we did not find a significant interaction effect for non-target issues (see Figure 2, right-hand diagram), $F(2,199)=1.35, p=$ $.26, \eta^{2}=.01$. The three disassociation effects (text-plus-visual $d=-0.46$, textonly $d=-0.40$, visual-only $d=-0.20$ ) did not significantly differ from each other.

Despite the failure to achieve significance, (descriptive) data analysis reveals a consistent pattern: The rank order is the same for the three modalities of presentation with regard to the size of the association as well as the disassociation effects. Taken together, we found only partial support for H3. There was only a weak moderation effect found for association effects.

\subsection{Consequences on voting intentions}

H4 predicted that mental party-issue links altered by political print advertising content influence voting intentions for that party. However, this effect should be stronger for those with more positive evaluations of the advertisements (H5). We used a regression-based approach to test this hypothesis (see Hayes, 2013). Hierarchical multiple-regression analysis was undertaken. By using post-exposure voting intentions as the outcome and pre-exposure voting intentions as a covariate, we were able to assess the advertising effect as change over time. Thus, we put pre-exposure voting intentions in the first block of the model. In the second block, we included the dummy-coded experimental condition variable to control for experimental manipulation. In the third step, we included the strength of the size of the association effect as well as the strength of the size of the disassociation effect. Both are indicative for AAS effects. We calculated a post-pre difference score for target attributes (i.e., association effect) as well as a pre-post difference score for non-target attributes (i.e., disassociation effect). ${ }^{2}$ The higher these difference scores, the stronger the (dis)association effects elicited by the advertising content. Furthermore, we included attitudes toward the ad in the fourth step and the two interaction terms (one for target attributes and one for non-target attributes) in the fifth step. H4 was tested by

2 As the disassociation effect's coefficient has a different sign-association effects increase party-issue links, the disassociation effects decrease party-issue links -, we calculated the pre-post difference (instead of the post-pre difference) for disassociation effects. This makes the interpretation of the regression analysis easier: The use of the pre-post difference ensures that higher values are indicative for stronger disassociation effects. 
looking at the increase in the predictive power of the third step (consequences of AAS on voting intentions, expressed as simple 'main effects'). H5 was tested using the increase in the predictive power of the fifth step (moderation assumption). Table 1 presents the results of this analysis.

Table 1: Hierarchical regression of post-exposure voting intentions on pre-exposure voting intentions, AAS association and disassociation effects, attitudes toward the ad, and two interaction terms.

\begin{tabular}{|c|c|c|c|c|c|}
\hline Variable & B & $S E(B)$ & $\beta$ & $p$ & $\Delta R^{2}$ \\
\hline Step 1 & & & & & $.22^{\star \star}$ \\
\hline Pre-exposure voting intentions & 0.67 & 0.09 & .47 & $<.01$ & \\
\hline Step 2 & & & & & .00 \\
\hline Pre-exposure voting intentions & 0.67 & 0.09 & .47 & $<.01$ & \\
\hline Experimental Group (D1) & 0.23 & 0.26 & .06 & .39 & \\
\hline Experimental Group (D2) & 0.13 & 0.26 & .03 & .62 & \\
\hline Step 3 'Main effects' of AAS & & & & & $.10^{\star *}$ \\
\hline Pre-exposure voting intentions & 0.71 & 0.08 & .50 & $<.01$ & \\
\hline Experimental Group (D1) & 0.26 & 0.25 & .07 & .31 & \\
\hline Experimental Group (D2) & 0.03 & 0.25 & .01 & .91 & \\
\hline Association effect & 0.28 & 0.06 & .28 & $<.01$ & \\
\hline Disassociation effect & -0.15 & 0.09 & -.10 & .12 & \\
\hline Step 4 & & & & & $.24^{\star \star}$ \\
\hline Pre-exposure voting intentions & 0.48 & 0.07 & .34 & $<.01$ & \\
\hline Experimental Group (D1) & -0.04 & 0.20 & -.01 & .84 & \\
\hline Experimental Group (D2) & -0.26 & 0.20 & -.07 & .20 & \\
\hline Association effect & 0.17 & 0.05 & .17 & $<.01$ & \\
\hline Disassociation effect & -0.04 & 0.08 & -.03 & .61 & \\
\hline Attitudes toward the ad & -1.15 & 0.11 & -.54 & $<.01$ & \\
\hline Step 5 Moderation effect & & & & & $.02^{*}$ \\
\hline Pre-exposure voting intentions & 0.48 & 0.07 & .34 & $<.01$ & \\
\hline Experimental Group (D1) & -0.02 & 0.20 & -.01 & .91 & \\
\hline Experimental Group (D2) & -0.27 & 0.20 & -.08 & .17 & \\
\hline Association effect (Ass) & 0.58 & 0.17 & .58 & $<.01$ & \\
\hline Disassociation effect (Disass) & 0.13 & 0.21 & .08 & .55 & \\
\hline Attitudes toward the ad (Aad) & -0.89 & 0.16 & -.42 & $<.01$ & \\
\hline Interaction Ass X Aad & -0.16 & 0.06 & -.41 & .01 & \\
\hline Interaction Disass X Aad & -0.05 & 0.08 & -.09 & .51 & \\
\hline
\end{tabular}

Note: Total $F(8,192)$ for Step $4=41.47, p<.001, R^{2}=.58$, Adjusted $R^{2}=.56$; for $\Delta R^{2}$ of each step: ${ }^{*}<.05, * \star<.01$. Experimental Group D1 (Dummy 1, $1=$ visual-only), Experimental Group D2 (Dummy 2, 1 = text-plus-visual). 
When looking at the data for the third step, the strength of the AAS association effect significantly predicted voting intentions $(\beta=.28)$. Thus, the stronger the political advertising's impact on the mental party-issue links, the stronger the positive change into more favorable voting intentions. The disassociation effect decreased voting intentions on a descriptive level $(\beta=-.10)$, although the size of this effect did not achieve significance. The negative sign, however, indicates that the more the political advertising exposure delinked the nontarget attributes, the weaker the voting intentions. The consequences of the AAS effect on voting intentions, as indicated by the significant change in $R^{2}$ of the third step, $F(5,195)=18.62, p<.001, R^{2}=.32$, Adjusted $R^{2}=.31 ; \Delta R^{2}=.10$, $p_{\Delta}<.001$, is substantial. On a most basic level, the data support H4.

The 'main effect' of AAS' association effect was qualified by a moderation effect, as indicated by a significant change in $R^{2}$ of the fifth step $F(8,192)=$ 32.61, $p<.001, R^{2}=.58$, Adjusted $R^{2}=.56 ; \Delta R^{2}=.02, p_{\Delta}=.036$. Only the interaction term including the association effect significantly contributed to moderation $(\beta=-.41)$. The interaction term including the AAS disassociation effect did not significantly differ from zero $(\beta=-.09)$.

Conditional effects were analyzed using the Johnson-Neyman technique (Hayes, 2013): The moderator value defining the Johnson-Neyman significance region was 3.01. This value is indicative of a moderate/neutral attitude toward the ad (possible range: 1-5; lower values are indicative of a more positive evaluation). The moderator value suggests that the strength of the AAS association effect positively predicted favorable voting intentions but only in individuals who positively evaluated the print advertisements (i.e., attitudes toward the ad $<3.01)$. Taken together, the evidence supports H5.

\subsection{Additional analysis}

We tested whether exposure to the advertisements changed the voting intentions. As can be seen in Table 1 (second step), the pre-post change was not dependent on the experimental condition (modality of presentation). Nevertheless, we found that exposure to the advertisements-regardless of the modality of presentation-increased voting intention: The sample showed more favorable voting intentions after exposure $(M=2.93, S D=1.70)$ compared to before $(M=1.75, S D=1.20), t(63)=10.80, d=0.80, p<.001$. This is a strong effect according to Cohen (1988). 


\section{Discussion}

We investigated AAS effects of political advertising, pairing a novel political party with the issues of environment and education using a controlled experimental design. Political advertising set the agenda of the novel party and thus filled out the parties' picture in the participants' heads (Lippmann, 1922; McCombs, 2005). We found that AAS could lead to association effects as well as disassociation effects. Of primary importance, association effects are dependent on the modality of presentation, with information presented verbally plus visually (dual-modal presentation) eliciting the strongest effects. The moderation effect of the modality of presentation was, however, not strong: Visualonly advertising content - without verbal language's set of syntactic devices for making explicit propositional statements (Messaris and Abraham, 2001) was also able to elicit substantial AAS effects. Furthermore, we looked at the consequences of AAS on voting intentions. The analysis revealed that the stronger the AAS effect was, the higher the likelihood was that participants would vote for that party. These consequences could be found only in those who rated the advertising content favorably.

\subsection{Implications of AAS's association and disassociation effects}

We already pointed to the fact that political advertising is the dominant form of direct communication between political parties and citizens (Kaid, 2004). From a campaigner's perspective, association effects are intended attribute gains. The campaigner's budget and the citizens' attention capabilities are limited, and advertising strategies thus have to rely on a restricted set of issues. Therefore, disassociation effects involving issues that are not advertised but which would nevertheless be beneficial for the party can have negative consequences. Disassociation effects can be perceived as unintended attribute losses when the non-advertised attributes are indeed deemed as beneficial for the party. Disassociation effects have no (or even beneficial) consequences when the attributes are deemed as unimportant (or unsupportive) for the party. The additional consideration of possible disassociation effects is important and should be a part of the campaigner's toolbox. This is especially important in situations when communication strategies are thought to be changed, for example, after a loss on election day (new issues for new target audiences).

In addition to the campaigner's perspective, political advertising can also play an important role in democracy from a normative perspective. It has the 
power to increase citizens' political knowledge regarding party-issue links, with relevance, for instance, during elections. As the goal of elections is to associate the policy preferences of the electorate with the political decisions of the elected representatives (Powell, 2000), high knowledge levels with regard to party-issue links - strengthened by association effects - can be deemed as beneficial for the democratic process. In contrast to the campaigner's interpretation, normative theorizing on democracy would also perceive disassociation effects to be positive because high knowledge levels of the issues which parties do not endorse can be deemed as beneficial in terms of tying the policy preferences of the electorate to the political decisions of the elected representatives (Powell, 2000). Disassociation effects increase citizens' ability to discriminate between different parties.

Although it seems plausible to solely rely on text-plus-visual advertisements for political parties due to their potential to elicit strong AAS effects, this modality of presentation - as the (descriptive) statistics indicated - produced the strongest disassociation effects as well. Thus, campaigners have to consider the possible gains (association effects) as well as the possible losses (disassociation effects) when deciding on the specific modality of presentation. When the consequences of possible losses are high, a reliance on visual-only advertising may be a better strategy, because these ads also produce a strong association effect.

\section{Limitations}

As with every study, the present one has its limitations. First, we used a novel political party as the AAS object of focus. This is an important restriction for the generalizability of our findings, as the process for established political parties might be much more complex because of more intertwining variables. We decided to use a novel party because it allowed us to study AAS under a controlled setting. Future research can test whether the same findings can be obtained when using established parties.

Second, it is important to note that the agenda of attributes can also consist of other attributes than those of issues. We used issues as the attribute of focus because issues are an important factor in the political process (e.g., McCombs and Shaw, 1972). However, as the perennial criticism of political advertising's trivializing of the political discourse by concentrating more on candidate personalities and images shows (Kaid, 2004), more 'human-oriented' attributes such as candidate images are important attributes as well. 
Third, visuals differ in their power to elicit variable interpretations (Abraham and Appiah, 2006; Coleman, 2010; Messaris and Abraham, 2001). We tried to use visuals that resonated with the verbal content. For example, for the advertisement with the slogan "More bikeways" in the text-only version, a visual showing a bikeway was used in the visual-only version. It is important to note that the mere presence of bikeways does not implicate the proposition "More bikeways". Mere visuals of bikeways can elicit variable interpretations. Although the selection of visuals was successful in the present study, as the substantial effects of the visual-only advertisements showed, the selection of pictures for visual-only advertisements should be treated with caution. The visuals should resonate with the verbal statement to improve learning by stimulating new supporting associations in memory.

Fourth, a non-representative sample acquired through online advertisements was used for economic reasons. Most of the study participants were students, female, highly educated, and showed a leaning toward the political left. Although the use of student samples has its limitations, we see it as suitable in the present context. Nevertheless, future research should replicate the findings with more representative samples.

Fifth, we measured party-issue links by asking the participants which of the issues they associated with the novel party. The list of issues was a priori defined and thus fixed. Future research can replicate the findings of the present study by using an open-ended response format.

\section{Conclusions}

AAS predicts that political advertising may influence how citizens think and feel about a political party by selecting and placing emphasis on certain attributes and ignoring others. We found that political advertising's emphasis on target issues contributed to the development of specific issues becoming mentally linked to the party in citizens' minds. These AAS effects are not without consequences, as the influences on voting intentions showed.

\section{References}

Abraham, L., \& Appiah, O. 2006. Framing news stories: The role of visual imagery in priming racial stereotypes. The Howard Journal of Communication 17. 183-203.

Anderson 2007

Atkin, C. 1973. Instrumental utilities and information seeking. In P. Clarke (Ed.), New models for mass communication research (vol. 2, pp. 205-242). Beverly Hills, CA: Sage. 
Atkin, C., \& Heald, G. 1976. Effects of political advertising. Public Opinion Quarterly 40. 216-228.

Belanger, E., \& Meguid, B. 2008. Issue salience, issue ownership, and issue-based vote choice. Electoral Studies 27. 477-491.

Brosius, H.-B., Holicki, S., \& Hartmann, T. 1987. Einfluß der Gestaltungsmerkmale von Wahlplakaten auf Personenwahrnehmung und Kompetenzzuschreibung [The organizational influence of election posters and personal perception write-ups]. Publizistik 32. 338-353.

Budge, I., \& Farlie, D. J., 1983. Explaining and predicting elections: Issue effects and party strategies in twenty-three democracies. London: Allen \& Unwin.

Burgoon, J. K. 1985. The relationship of verbal and nonverbal codes. In B. Dervin \& M. J. Voight (Eds.), Progress in communication sciences (vol. 6, pp. 263-298). Norwood, NJ: Ablex Publishing Corporation.

Cohen, J. 1988. Statistical power analysis for the behavioral sciences. Hillsdale, NJ: Lawrence Erlbaum Associates.

Coleman, R. 2010. Framing the pictures in our heads: Exploring the framing and agendasetting effects of visual images. In P. D'Angelo and J. Kuypers (Eds.), Doing news framing analysis: Empirical, theoretical, and normative perspectives (pp. 233-261). New York, NY: Routledge.

Collins, A. M., \& Loftus, E. F. 1975. A spreading-activation theory of semantic processing. Psychological Review 82. 407-428.

Domke, D., Shah, D., \& Wackman, D. 1998. Media priming effects: Accessibility, association, and activation. International Journal of Public Opinion Research 10. 51-74.

Entman, R. M. 1993. Framing: Toward clarification of a fractures paradigm. Journal of Communication 43. 51-58.

Greenwald, A. G., Banaji, M., Rudman, L., Farnham, S., Nosek, B., \& Mellot, D. 2002. A unified theory of implicit attitudes, stereotypes, self-esteem, and self-concept. Psychological Review 109. 3-25.

Gregg, A., Seibt, B., \& Banaji, M. 2006. Easier done than undone: Asymmetry in the malleability of implicit preferences. Journal of Personality and Social Psychology 90. 1-20.

Gunter, B. 1987. Poor reception: Misunderstanding and forgetting of broadcast news. Hillsdale, NJ: Lawrence Erlbaum Associates.

Hayes, A. 2013. Introduction to mediation, moderation, and conditional process analysis: A regression-based approach. New York, NY: The Guilford Press.

Kaid, L. L. 1999. Political advertising: A summary of research findings. In B. Newman (Ed.), The handbook of political marketing (pp. 423-438), Thousand Oaks: Sage.

Kaid, L. L. 2004. Political Advertising. In L.L. Kaid (Ed.), Handbook of political communication research (pp. 155-202). Mahwah, NJ: Lawrence Erlbaum Associates.

Krugman, H. 1965. The impact of television advertising: Learning without involvement. Public Opinion Quarterly 29. 349-356.

Lessinger, E.-M., Moke, M., \& Holtz-Bacha, C. 2003. "Edmund, Essen ist fertig!” Plakatwahlkampf 2002 - Motive und Strategien [“Edmund, supper is on!” Motives and strategies in 2002 political poster campaigning]. In C. Holtz-Bacha (Ed.), Die Massenmedien im Wahlkampf. Die Bundestagswahl 2002 (pp. 216-242). Wiesbaden, Germany: Westdeutscher Verlag.

Lippmann, W. 1922. Public opinion. New York, NY: Macmillan. 
Lutz, R., McKenzie, S., \& Belch, G. 1983. Attitude toward the ad as a mediator of advertising effectiveness: Determinants and consequences. Advances in Consumer Research 10. 532-539.

Martinelli, K. A., \& Chaffee, S. H. 1995. Measuring new-voter learning via three channels of political information. Journalism \& Mass Communication Quarterly 72. 18-32.

McCombs, M. 2005. A look at agenda-setting: Past, present and future. Journalism Studies 6. 543-557.

McCombs, M., Llamas, J., Lopez-Escobar, E., \& Rey, F. 1998. Candidate images in Spanish elections: Second-level agenda-setting effects. Journalism \& Mass Communication Quarterly 74. 703-717. doi:10.1177/107769909707400404

McCombs, M., Lopez-Escobar, E., \& Llamas, J. 2000. Setting the agenda of attributes in the 1996 Spanish general election. Journal of Communication 50. 77-92. doi:10.1111/ j.1460-2466.2000.tb02842.x

McCombs, M., \& Shaw, D. 1972. The agenda-setting function of mass media. Public Opinion Quarterly 36. 176-187. doi:10.1086/267990

McCombs, M., \& Shaw, D. 1993. The evolution of agenda-setting research: Twenty-five years in the marketplace of ideas. Journal of Communication 43. 58-67. doi:10.1111/ j.1460-2466.1993.tb01262.x

McNamara, T. 2005. Semantic priming. Perspectives from memory and word recognition. New York, NY: Psychology Press.

Messaris, P., \& Abraham, L. 2001. The role of images in framing news stories. In S. Reese, O. Gandy \& A. Grant (Eds.), Framing public life. Perspectives on media and our understanding of the social world (pp. 215-226). Mahwah, N): Lawrence Erlbaum Associates.

Paivio, A. 1986. Mental representations: A dual-coding approach. New York, NY: Oxford University Press.

Petrocik, J. R. 1996. Issue ownership in presidential elections, with a 1980 case study. American Journal of Political Science 40. 825-850.

Petty, R. E., \& Cacioppo, J. T. 1986. Communication and persuasion: Central and peripheral routes to attitude change. New York, NY: Springer-Verlag.

Powell, G. B. 2000. Elections as instruments of democracy: Majoritarian and proportional visions. New Haven, CT: Yale UP.

Roskos-Ewoldsen, D. R., Roskos-Ewoldsen, B., \& Carpentier, F. D. 2009. Media priming. An updated synthesis. In J. Bryant \& M. B. Oliver (Eds.), Media effects. Advances in theory and research (pp. 74-93). New York, NY: Taylor and Francis.

Scheufele, D., \& Tewksbury, D. 2007. Framing, agenda setting, and priming: The evolution of three media effects models. Journal of Communication 57. 9-20.

Tankard, J., Hendrickson, L., Silberman, J., Bliss, K., \& Ghanem, S. 1991. Media frames: Approaches to conceptualization and measurement. Paper presented at the annual convention of the Association for Education in Journalism and Mass Communication, August 1991, Boston, MA.

Van den Bulck, J. 1993. Estimating the success of political communication strategies: The case of political poster impact in a Belgian election. European Journal of Communication 8. 471-489.

Walgrave, S., Lefevere, J., \& Nuytemans, M. 2009. Issue ownership stability and change: How political parties claim and maintain issues through media appearances. Political Communication 26. 153-172. 


\section{Appendix}

Advertisements used in the experiment.

\begin{tabular}{lll}
\hline text-only & visual-only & text-plus-visual \\
Faire Universitätszugänge & für alle.
\end{tabular}

education 1: "Fair access to universities."
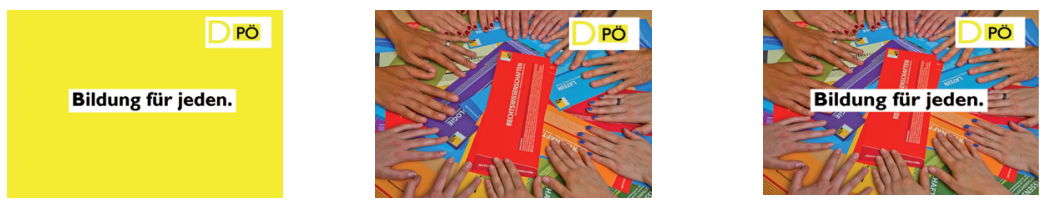

education 2: "Education for everyone."
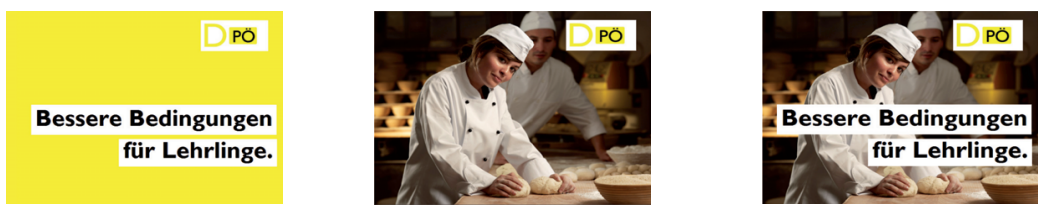

education 3: "Better conditions for apprentices."
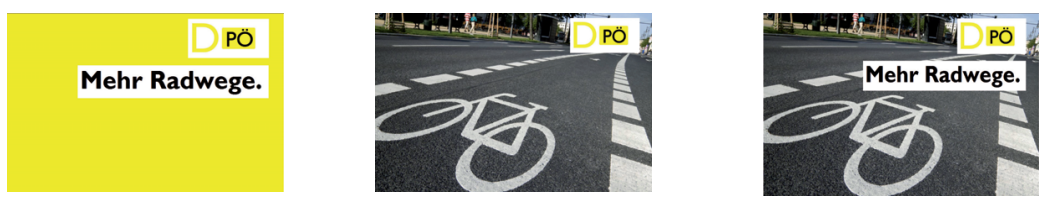

environment 1: "More bikeways."
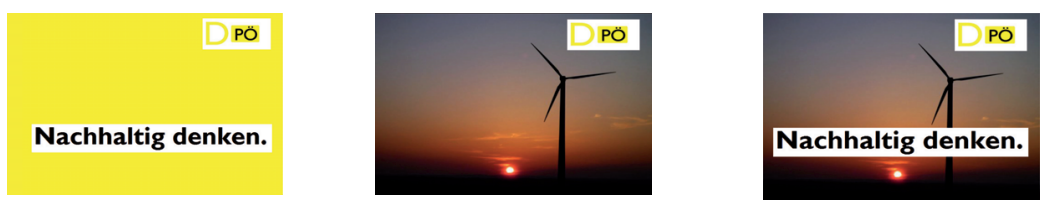

environment 2: "Think sustainable."
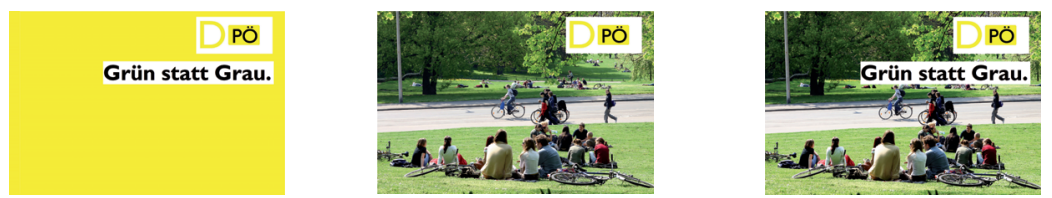

environment 3: "Green instead of grey." 